\title{
Sweden's Capacity to Prepare and Respond to a Terrorist Attack on Rail-Bound Traffic - Promising Practices and Obstacles to Inter-Organizational Collaboration
}

\author{
Veronica Strandh \\ Department of Political Science \\ andCentre for Research and Development \\ in Disaster Medicine, Department of Surgery, Umeå University, \\ SE-90187, Umeå, Sweden \\ E-mail:veronica.strandh@umu.se
}

Received 11 August 2015

Accepted 15 November 2015

\begin{abstract}
This article takes an interest in evolving collaborative practices in crises caused by terrorism targeting rail-bound traffic. Sweden provides the empirical focus, by examining current preparedness processes, this article offers an important perspective on inter-organizational collaboration; that is, the perspective of the involved actors themselves. This study relies on 20 interviews with key actors in the response system and rail bound traffic actors. This article combines insights from the literature on governance with the research on disasters and crises. Promising practices and obstacles to inter-organizational collaboration are identified and analyzed.
\end{abstract}

Keywords: Crisis response, terrorism, rail-bound traffic, networks, crisis management actors

\section{Introduction}

Terrorism continues to plague societies, and major mass-casualty terrorist events in the past have demonstrated how complicated and organizationally demanding the crisis response to such events is. Crisis management, including both preemptive and preparatory efforts as well as response and recovery actions, requires the knowledge, resources, and interactions between many different types of organizations (Dynes 1970; Mileti 1999). The importance of collaborative actions in crisis management has been stressed by both practitioners and researchers. In fact, there is a vast body of literature suggesting inter-organizational collaboration as a success factor in effective crisis management (Boin and 't Hart 2010; Moynihan 2009). However, in practice, it turns out that collaborative actions are often difficult and imbued with challenges (Boin and Bynander 2014). Therefore, how to achieve inter-organizational collaboration in crisis management continues to be a topic for scholarly attention. Not least, it is an ongoing discussion within the disaster and crisis management field, in which scholars seek to gain a better understanding of the ideas, resources, and interactions taking place in collaborative response networks (Comfort, Boin, and Demchak 2010; Crunin et al. 2015; $\mathrm{Hu}$, Knox, and Kapucu 2014; Kapucu 2008; Kapucu 2012).

This article sets out to contribute to that discussion by studying collaborative efforts in the context of terrorist-induced crises. More specifically, this article takes an interest in evolving collaborative practices in crises caused by terrorism targeting rail-bound traffic. Thus, in terrorists' attempts to maximize the number of casualties from their terror events, rail-bound traffic has become an attractive target (Jenkins 2001, 2012; Strandberg 2013; Waugh 2004).

Sweden provides the empirical focus, and by examining the ongoing processes to enhance the 
capacity in Sweden to prepare for and respond to a major terrorist attack on rail-bound traffic, this article offers an important perspective on inter-organizational collaboration; that is, the perspective of the involved actors themselves. This study relies on 20 interviews with key actors in the response system and major rail operators and railway authorities in Sweden. The following questions are posed: How do the different actors perceive the threat of terrorism, and how do they experience their respective roles in enhancing the preparedness capacity for responding to a terrorist attack on rail-bound traffic? In terms of interorganizational collaboration, what do the different actors perceive as promising practices and obstacles to their current crisis management capacity?

The outline is as follows: the next section begins with a short background, followed by a section presenting the perspective applied to analyze the research questions. In order to understand the complexity associated with inter-organizational collaboration, this article combines literature on governance with the crisis and disaster literature that focuses on collaborative response networks. The notes on methodology then follow. A fictional scenario of a multi-site terrorist attack targeting rail-bound traffic in Sweden's capital, Stockholm, was developed and used during the 20 interviews. The findings from the interviews are structured to reflect practices in different phases of crisis management, with a special focus on preparedness and response practices. The concluding section discusses the main findings and answers the research questions posed.

\section{Background}

Sweden has experienced major crises, including the Estonia ferry disaster in 1994 and the assassinations of the prime minister in 1986 and the minister of foreign affairs in 2003, as well as suffered greatly from the Indian Ocean tsunami in 2004. In the 1970s, the country suffered from acts of terrorism, including the Bulltofta skyjacking event in 1972 and the seizure of the West German Embassy in 1975 (Hansén 2007). However, Sweden has no experience of managing terroristinduced crises that have resulted in major mass-casualty situations. Thus, it is reasonable to believe that actors in Sweden suffer from a so-called paucity of experience problem (Levitt and March 1988). It is assumed that a management and knowledge gap exists in terms of the practical experience of dealing with a mass-casualty event caused by terrorism. Nevertheless, Sweden now faces a situation when the palette of risks, hazards, and vulnerabilities is changing. Terrorism is increasingly often identified as a concern in many public organizations' risk and vulnerability analyses, and we can therefore assume that preparedness practices are also taking place for terrorist-induced crises.

A terrorist attack on rail-bound traffic in Sweden will require response actions from fire fighters, emergency medical personnel, police, intelligence agencies, and crisis actors at different levels of government. In addition, transportation actors are assumed to participate. In the case of Sweden, it happens that rail-bound traffic is a deeply fragmented environment; no less than 17 companies are running passenger traffic and 21 companies are running freight traffic (registered members at ASTOC 2015). Hence, an attack on rail-bound traffic would affect and require actions from a multitude of different actors.

The many different actors are is expected to operate in complex networks under the guiding norm of interorganizational collaboration. Characteristic for the Swedish response system is its very strong emphasis on shared and collaborative actions in crisis management (Wimelius and Engberg 2014). The importance of collaboration isfirmly embedded in policy documents central for crisis management such as government bill Cooperation in emergency - for a more secure society (2005/06:133) and government communiqué Society's crisis preparedness: strong collaboration for increased safety (2009/10:124). Moreover, one can observe how the centrality of inter-organizational collaboration is reflected in the actual daily language used by practitioners in the field; there are collaboration courses, collaboration conferences, collaboration exercises, forums for cooperation and collaboration, etc.

Danielsson, Johansson, and Kvarnlöf (2013:17) make a telling observation about inter-organizational collaboration in Sweden: "the concept of interorganizational coordination has sunk in to the point where it is imbued with ideological rather than practical meaning; coordination has become a goal in and of itself, as opposed to being a means to an end." It illustrates how the particular concept of interorganizational collaboration has reached a rather exceptional position in the Swedish crisis management context. Hence, empirically speaking, Sweden constitutes an interesting case to further explore, the support for collaborative actions appears to be resounding. However, in the particular context of collaborative preparedness for a terrorist-induced crisis targeting rail-bound traffic in Sweden, there is no previous systematic research. In addition, and analytically speaking, Sweden is also an informative case when aiming to gain a better understanding of how organizations operate in collaborative, networked environments. Hence, during the last decade, public services in Sweden have become increasingly characterized by collaborations and networked forms of organization. 


\section{Collaborative Actions and Network Theory in Crisis Management}

In the endeavor to understand collaborative actions in crisis management, this article combines insights from the literature on governance with the research on disasters and crises. In line with researchers such as Drabek (2007) and Moynihan (2009), interorganizational collaboration is used as the key concept. The terminology appears problematic because it varies extensively. Inter-organizational coordination, collaboration and cooperation, multi-agency cooperation, and cross-sectorial cooperation are often used interchangeably in both crisis research and governance literature. However, the author interprets the core of the concept inter-organizational collaboration as referring to the fact that organizations need knowledge and resources from other organizations; therefore, they need to interact in networks to achieve a common goal.

A great amount of researchers have drawn attention to how overarching changes are taking place in crisis management. The American response system is frequently studied, not least since the September 11 attacks. Hu et al. (2015) drew attention to how the American emergency management system has gradually shifted from a centralized command and control system to a more collaborative approach. Such a development can also be observed in other countries. It is common to contrast a traditional hierarchal response system to a horizontal, networked system. An overwhelming bulk of the crisis and disaster research stresses how hierarchical networks perform poorly under crisis because they are assumed to isolate large networks from each other. Instead, a more horizontal form of collaboration is increasingly put forward as the preferred system (Comfort 2007; Dynes and Quarantelli 1977; Kapucu 2006; Moynihan 2008). A fundamental assumption is that society's many "complex threats" require the involvement of a multitude of actors, including their combined knowledge and resources (Handmer and Dovers 2013).

The observed shift in how crisis management is organized also relates to a broader discussion on political steering and public administration, which according scholars have - using a common formulation, "experienced a shift from government to governance" (Rhodes 1996; Peters and Pierre 1998). This shift is described as a movement away from principles such as bureaucracy and command and control in favor of collaboration and flexibility. Klijn and Koppenjan (2000:130) described the characteristic of the network approach as: "policy is made in complex interaction processes between a large numbers of actors which takes place within networks of interdependent actors." This shift from government to governance not only implies a change in structure but also opens up for a greater influx of different ideas and views among the many actors. One can here refer to "frame reflection" (Schön and Rein 1994), which makes us aware of how different actors make strategies based on their own frame. Therefore, we must assume that there might be several frames present in collaborative networks, thus indicating different views on solutions as well as problems in networks.

As stated, a more horizontal form of collaboration in crisis management has support in research. The benefits from collaborative networks can vary depending on context; however, in the context of complex crises, some aspects are frequently highlighted in the literature. Networks are seen as flexible and are thereby regarded as effective in crisis situations. According to Comfort (2007), a key characteristic of collaborative actions is that the participating actors align their activities voluntarily. Therefore, the importance of personal relations and trust is often mentioned in this regard. Building confidence among actors is seen as a key to reduce the costs of collaboration (Coleman 1990; Edelenbos and Klijn 2007). Networked forms of collaboration are also assumed to enable rapid dissemination of information among their members, which in turn is assumed to enable collective sensemaking (Weick 1988). Comfort (2007) argued how cognition, understood as the capacity to recognize the degree of emerging risks and act on such information, is central to crisis management practices. Moreover, networked systems are assumed to foster creativity, an aspect which is frequently regarded as important in complex crisis management processes (Kapucu 2008).

In light of examining inter-organizational collaboration in the context of rapid evolving crises, which are associated with stress, uncertainty, and time pressure (Boin et al. 2005), the actual management of response networks becomes crucial. Klijn and Koppenjan (2012) underlined how networks require guidance and management. When the management of networks is discussed in the literature, the state is often referred to as being an enabler of collaboration and coordination, and its steering capacities should seek to unite the various perceptions of actors, thus including negotiating skills (Klijn and Koppenjan 2000).

The bottom line of the governance literature, and the crisis research that focuses on networked forms of crisis management, can be interpreted somewhat simply as complex problems should be met with complex network solutions; therefore, a question arises: is it so easy? One should be aware that the network approach has encountered criticism; for instance, it is criticized for placing too much emphasis on collaboration and thereby downplaying the risk of conflict and power differences. Moreover, critics argue that the approach considers 
government organizations to be seen as any other organization, neglecting their role as "guardian[s]" of the public (Brans 1997; Klijn and Koppenjan 2012). One can also refer to Moynihan (2008), who emphasized the complexity of the so-called "crisis management paradox," which means that crises require an inter-organizational response, while at the same time requiring rapid and decisive coordination, which is seen as an inherent challenge to networks.

Thus, there are diverging views of collaborative networks. In our endeavor to understand collaborative actions in the context of terrorist-induced crises directed against rail-bound traffic in Sweden, questions were raised during the interviews that, in different ways, captured the dynamics of in-organizational collaboration with regard to both the presumed merits and limits.

\section{Methodology}

Empirically, this article builds on 20 semi-structured interviews with actors who have a central role in preparing and responding to terrorism targeting railbound traffic. The main data collection was carried out between February and November 2014, and the interviews were conducted in person. A broad range of organizations were included: 1) First responders at an operational and at a strategic level (the police, the security service, the fire service, and the medical services); 2) actors from rail-bound traffic (key actors in the scenario include $\mathrm{SJ} A B$, A-Train AB, MTR Stockholm, Jernhusen, the Swedish Transport Agency, and the Swedish Transport Administration); and 3) representatives from central actors in the response system such as the City of Stockholm, the County Administrative Board in Stockholm, and the Civil Contingencies Agency (MSB). A scenario-based methodology has guided the research. A terrorist attack scenario was developed in which Stockholm was struck by four bomb explosions. The merit of using scenariobased interviews is that practitioners in the field of crisis management are used to working with scenarios in various methods as a way to plan for potential future crises (Stern and Sundelius 2002). A scenario was also useful since it indicated the scale of the attack and thereby reduced the risk that the term preparedness or response capacity had very different meanings for the interviewee and researcher. Moreover, a semi-structured interview guide, capturing different aspects of interorganizational collaboration, was used. The data were later transcribed by the author and analyzed on the basis of the pre-defined themes: threat perception, preparedness activities, immediate response capacity, inter-organizational collaboration, recovery, and learning processes.

\section{Analysis}

\subsection{Crisis Management in Sweden}

The Swedish crisis management system is often described according to its three guiding principles. The principle of responsibility establishes that the authority who has responsibility over an activity under normal circumstances will remain the responsible authority during a crisis. The principle of parity states that an activity during a crisis should, as far as possible, be carried out in the same manner as it would under normal situations. The principle of proximity implies that a crisis should be managed at the lowest possible level (krisinformation.se 2012). Municipalities have geographic responsibilities at the local level. The 21 county administrative boards have a geographic responsibility at the regional level. They have an important role in coordinating society's preparedness through, for example, exercises and risk and vulnerability analyses. At the time of a major crisis, the county administrative board has an important function to coordinate different measures with relevant actors (Government Bill 2007/98:92). Moreover, at the regional level, county councils play a central role when it comes to providing health care and ensuring that there is disaster medicine preparedness in place (The National Board of Health and Welfare 2013). At the national level, the political responsibility for civil crisis preparedness belongs to the Ministry of Justice, which acts through the Swedish Civil Contingencies Agency.

There is also a Crisis Management Coordination Secretariat at the Government Offices in order to handle cross-sector crises in a coordinated way (Ministry of Justice 2014)

\subsection{Preparedness Practices}

A starting point for examining ongoing processes to enhance the capacity in Sweden to prepare for and respond to a major terrorist attack on rail-bound traffic is with the joint efforts carried out early in the process. Given the many different involved actors, one can assume that the perceptions of the nature and extent of the actual hazard, in this case terrorism, might vary. Interviewees were asked to describe how they perceived the threat of terrorism against Sweden and how they viewed the risk of an attack targeting rail-bound traffic. The three quotations below illustrate the most recurring reflections.

"Absolutely, it is not unlikely that it might happen. It is likely that it is going to happen; the only question is when?" (Interview 5). 
"It is going to happen. So, it is good to be as prepared as can be" (Interview 12).

"I don't know how today's terrorists think, but historically-Madrid, London-there's a tendency for them to appreciate rail-bound traffic as a target. Why wouldn't they be thinking the same thing in Sweden, if the threat scenario is there?" (Interview 15).

Sweden is seen as a potential target for terrorism, and based on the logic that terrorists appear to target soft targets in order to achieve extensive damage, the interviewees found rail-bound traffic to be a likely target for attacks. Hence, the empirical material reveals a uniformed picture when it comes to the risk of an attack and its potential consequences. However, on the question of how each organization relates to the threat level and how knowledge and intelligence information are communicated in the current preparedness practices, a more ambiguous picture emerges.

The Swedish Security Service (Säpo) is perceived as the most central actor in the context of counterterrorism. The agency is also seen as a node or a source of information when other actors prepare for acts of antagonistic violence. However, the empirical material shows different views in how collaboration actually works between intelligence actors and other actors in the crisis response system. One line of reasoning that emerged during the talks was that the abilities to acknowledge risks and threats as well as take preventive actions belong to the domain of Säpo. Respondents expressed trust for their work, and they commented that they can only act upon their assessments. Another line of reasoning reveals how respondents perceive law enforcement, particularly Säpo, as working in a closed or protective manner. Hence, they experience a lack of information. The two different views are exemplified below:

"I trust that Säpo is doing their job and that they are conducting the right threat assessments; I can only act upon their information" (Interview 20).

"Sometimes it feels like a one-way communication. I have to call Säpo and ask, "is this affecting us?".... Even though they make all the decisions when it comes to threat levels and so forth, we at least need to be informed" (Interview 12).

Despite an awareness of the complexity of intelligence, several organizations stress the need for improved flows of information. However, at the same time and in a selfcritical manner, there seem to be uncertainties about the different organizations' capabilities to receive increased information and then adapt their behavior accordingly.
It is a precarious task to establish a link between a certain-threat scenario as well as prepare to manage the situation if the threat is realized. Training and exercises are common tools for enhancing preparedness. Since there are many players in a response to a large-scale crisis such as a terrorist attack, there are also different exercise routines. A training-intensive organization such as the fire brigade, which trains on a weekly (or daily) basis for a crisis situation, differs widely from a rail operator who conducts, in general, one to two trainings a year. This difference is expected due to their respective roles and responsibilities. Still, the essence of a more collaborative approach to crises implies that both public and private organizations are assumed to interact during crises; therefore, increased training opportunities, spanning over organizational boundaries that involve different cultures of working, are therefore regarded as important.

From an inter-organizational perspective, it is an interesting finding that the many different actors appear to prepare for terrorist-induced crises in profoundly different ways, and some of them - not at all. As stated, it is a shared perception that rail-bound traffic is at risk for terrorism, and most of the respondents find it likely that Sweden will suffer from an attack in the future. At the same time, however, one of the most obvious findings in the material is the disparate answers on whether there is a need to carry out training and preparedness exercises with a specific focus on terrorism.

"We do not practice how to respond to terrorism. I'm not sure, but I do not think that a crisis caused by terrorism differs from a crisis caused by something else" (Interview 10).

"Sometimes we practice a scenario including a bomb or so, but we never really practice all the extra dimensions one can assume come with a terrorist attack... You can assume for example, a second explosion, and when something like that occurs, I think we are not as prepared as one could wish" (Interview 3).

The two opinions expressed above come from two different people, each with a central operational function in the case of a major crisis, yet they present two diverging views. Hence, there seems to be a tension between those who practice or believe that it is necessary to practice terrorism-specific scenarios since they encompass particular security challenges and bring certain challenges, and there are others who believe that it is better to concentrate the available resources on practicing general and more recurring response challenges. 
A point of reference for collaborative preparedness practices is 2007, when MSB, which organizes the yearly multi-sector exercise "Samö," used a scenario simulating multiple attacks on rail-bound traffic in Stockholm. The evaluation report revealed a rather extensive critique of the response; interestingly, several aspects referred to inter-organizational collaboration. A lack of routines for establishing a shared perception of the threat level and shortcomings in coordinating communication to the media and the public were identified as critical aspects (MSB 2007). This particular exercise was brought to our attention in several of the 20 interviews, and it appears to be a shared opinion that the preconditions for carrying out effective inter-organizational collaboration during the exercise were poor. Importantly, many respondents expressed that they have experienced progress since 2007; not least in terms of an increased commitment to work together. Yet, there has been no follow-up exercise on this particular scenario of a terrorist-induced crisis on rail-bound traffic since.

"I think that it is still rather controversial to talk about terrorism against rail-bound traffic... If an imminent threat against the railway system would emerge, how are we supposed to act? Who will work with this? Who speaks the language of law enforcement? Do we have security clearance?...It is one thing to collaborate during normal circumstances, but it is a completely different thing to collaborate when the actual crisis occurs." (Interview 4)

Hence, there are respondents who indicated that despite the obvious challenges identified in 2007, there is still much that remains to be done when it comes to preparedness for this particular terrorist-induced crisis.

\subsection{Response Practices}

As stated, in order to discuss collaborative response practices during the most acute phase of a crisis, a fictional scenario was developed. This scenario illustrates how central Stockholm has become the target for an unknown terrorist group. 1 Hidden in backpacks, the first bomb explodes at an $\mathrm{SJ}$ AB regional passenger train while still standing at the central station. Two subsequent explosions take place at a subway train between the two central stations: Hötorget and Rådamansgatan; and an additional bomb explodes at an Arlanda Express train heading for the international

\footnotetext{
${ }^{1}$ The scenario builds on an empirical overview of around 4,000 attacks carried out against rail-bound traffic between 1970-2010 (Strandberg 2013). Based on the 20 most large-scale attacks, a scenario has been developed.
}

airport. In all, the four bombs explode during a Friday morning rush hour in the short time span of 08.1208.16. It causes the deaths of 80 people, and 300 people are in need of immediate medical care. In addition, there is a large number of so-called walking wounded. The scenario also entails a full closure of the transportation system.

Each interviewee was asked to describe his or her immediate actions following the four bomb explosions, as depicted in the scenario. The reported tasks cover a wide range of activities. Core emergency management actions include saving lives, fighting fires, securing buildings, evacuating the train and subway system, conducting law enforcement procedures, collecting evidence, and responding to new threats. Several actors described their immediate tasks as being about coordination, such as coordinating distribution of information to the media, establishing a common progress report, sharing information, holding coordination meetings, and planning for future actions. Other actors interpreted their immediate actions to be about taking care of their own companies, such as activating catastrophe plans. Additional examples concerned activities such as electricity restoration, volunteer coordination, provision of food supplies, and supporting commuters. This description serves the purpose of underlining that one of the most obvious characteristics of the responding network in the case of a major attack on rail-bound traffic is its sheer size and the many tasks that are to be performed in the first critical hours.

Without a doubt, in terms of management skills and resources, the different actors anticipate that their collaborative response will face some critical challenges. Difficulties adhering to the initial sensemaking process appear as a main challenge. In particular, it was underlined by several respondents that it is assumed to be more difficult to make sense of the situation when it is a terrorist-induced crisis compared to a more recurring or familiar crisis situation:

\footnotetext{
"You need a common ground for how you approach incident sites after a terrorist attack...In today's situation, it would be like ants moving in on an anthill, from all directions, and each ant going to work on its own little bit" (Interview 3).
}

First responders express concern that a slow sensemaking process can have serious consequences in terms of security. The quotation above demonstrates how a respondent, who isfamiliar with working at incident scenes, anticipates how front liners will rush into the situation to save lives without carefully considering potential security risks. Further explosions and "dirty bombs" are other potential security dangers. Most first 
responders seem to agree that their usual quick response routines can become a vulnerability in these particular contexts since, most likely, they will not be reached by the information about the antagonistic nature of the attack before they have entered the site. A second point refers to the increased confusion that three different incident sites apply to the sense-making process. A third critical point refers to the dilemma of whether the police need to secure the site before ambulance and firefighters can gain access. If so, how long can such a decision take, considering the first "critical hour" and the need for people to receive immediate medical treatment?

It is highly important to remember that the immediate response to a multi-site attack takes place in a very time-critical environment. As the fictional scenario entails, the rail-bound traffic system becomes the target of bomb explosions. Persons injured in bomb explosions (and in shootings) tend to bleed to death, and meaningful life-saving efforts must be initiated extremely rapidly. Hence, much of the most imitated collaborative actions, taking place at the different incident sites, revolve around saving lives. A common formulation among the first responders interviewed for this study was "we will manage the situation, one way or another." However, the scale of the attack seems to add an extra dimension to the response and to collaboration in particular. The role of disaster medicine emerges here as central; that is, the capacity to handle demanding situations in which the available resources are insufficient in relation to the immediate need of medical care (Lennqvist 2005:300). A concern was expressed that the current resources invested in specific disaster medicine competence fall short. One respondent explained how it is reasonable to believe that, in the case of a major terrorist attack of the same scale as the scenario, the hospitals in Stockholm will be able to deploy a significant amount of medical personnel. However, the respondent questions to what extent the personnel hold a specific competence in disaster medicine.

"There is a belief that the local level-that is, hospitals and our many local health facilities-should also have a competence when it comes to disaster medicine. But in the world we are working in today, with so many demands on efficiency and demands on making profits, it's not going to happen. They many different actors will not invest in specific trainings or disaster medicine competence unless they are paid for, or unless it is a requirement." (Interview 15)

It is important to note that the scenario is taking place in the capital; thus, the preconditions for responding to an attack in more sparsely populated places in Sweden are different. It is emphasized in the interviews that the
Stockholm regionhas plenty of resources. For instance, the two major fire brigade organizations have around 30 fire stations at their disposal, and there are seven emergency hospitals in Stockholm. Yet, as the quotation below illustrates, one should not underestimate the enormous resources that a terrorist attack on rail-bound traffic would require:

"Although we might have plenty of resources in Stockholm, we cannot handle everything....Three different incident sites is an extremely demanding task to manage, and it would most likely require three separate command and control functions" (Interview $15)$.

At first, resources will be scarce and will not be available at the moment when the first bomb explodes. The medical "surge capacity" in Stockholm was described as consisting of seven emergency hospitals, 68 ambulances, one helicopter, and more than 200 health centers. Importantly, many of these resources are already in use on a daily basis, and access to intensive care beds is particularly challenging because they are already being used by critically ill patients who cannot be transferred to other places without difficulty. Thus, rapid action is necessary to make resources available and request assistance from other regions. Once again, referring to the scenario and its bomb explosions, we must expect that the injury pattern following the attack will include severe burn injuries. There are no special units for burn injuries in Stockholm; hence, rapid collaboration becomes crucial since the severely injured must be transported to the cities of Uppsala or Linköping.

So far, it has been illustrated how the immediate response to four bomb explosions tends to revolve around a specific "subnetwork" consisting of the ambulance, fire, and police services. Respondents report trust and confidence in the well-practiced interactions taking place among the front liners. Above all, first responders often have similar command structures and are used to working together, and they have a confidence in their respective roles. If we expand the horizon, collaborative networks in crisis management are not confined to specialized first responders and another subnetwork emerges. That is a network consisting of transportation actors; they are not specialized in crisis management, but they are nevertheless assumed to participate in interorganizational collaboration. In the fictional scenario used in this article, the railway operators, infrastructure owners, and transportation authorities, such as SJ AB, Arlanda Express, MTR Stockholm, Jernhusen, and the Swedish Transport Administration, are immediately affected and put under pressure. In contrast to first 
responders, rail-bound traffic actors' actions in the immediate response take place in more peripheral parts of the response networks; for example, assisting with buses at evacuations, providing information to passengers, or dealing with infrastructure damage.

Furthermore, respondents emphasized how a response to a terrorist attack in central parts of the capital will cause an initial chaos. Thus, in addition to established response procedures, many respondents stressed the need to "think outside the box." One cannot fully predict how a crisis will develop and which ad-hoc networks and ad-hoc solutions will take place. Respondents are open to the development that ad-hoc solutions can serve as a complement to (or even replace according to some) pre-planned procedures, such as turning sport venues into meeting points for relatives or stranded commuters. Although respondents expressed diverging views as to what extent and when volunteers can be utilized in the response, volunteers were mentioned as an additional subnetwork of potential resources.

Inter-organizational collaboration cannot only be understood in terms of the influx of resources and knowledge. In fact, a conclusion from the 22 July Commission in Norway (2012:19:1) is illustrative in this regard by concluding "resources count, but their use decides." Hence, all these potential resources put forth by the respondents also require management and coordination, which in turn requires clear roles and responsibilities among the many actors. In light of that, some reflections from the respondents deserve our attention:

"We have to concretize our efforts to enhance interorganizational collaboration. We cannot only emphasize it when we are participating in a meeting or workshop and then go home and do nothing" (Interview 4).

"From the perspective of organizational-collaboration, I think we are pretty well prepared. We should probably be able to take prompt collaborative actions. However, if your scenario, including hundreds of casualties, would actually occur, then I am not completely sure if we could 'manage the situation' or not" (Interview 15).

It appears as if the different organizations relevant in a response network, in the case of a major terrorist attack on rail-bound traffic, increasingly pay attention to interorganizational collaborations and actions to enhance knowledge about different subnetworks and how different ways of working and responsibilities take place. However, the empirical material also echoes a concern that increased knowledge about one another will not always turn into actual action. Therefore, several respondents referred in a positive manner to the Programme for Cooperation - Stockholm Region as a concrete example of inter-organizational coordination. The initiative that was taken after the coordination deficiencies during the "Samö 2007" was revealed. The County Administrative Board has a central function at this regional level, and additional participants include SOS Alarm, municipalities in Stockholm, the Stockholm County Council, representatives for public transport, fire, and rescue services, the Ports of Stockholm, and the Police Authority. The guiding idea outlines that efficient collaboration in everyday life will generate good preparedness and the ability to deal with a major incident in a time of crisis (Programme for Cooperation - Stockholm Region 2014).

The County Administrative Board plays a key role in carrying out recurrent collaboration conferences during a crisis, and interviewees expressed expectations that these meetings will "move the management forward" through establishing a common progress report and making decisions about how to proceed. The respondents were asked whether there are any concrete mechanisms to resolve possible differences in opinion among players in a collaboration conference. This is how one respondent answered:

"I actually don't know. It's about leadership, and in this case the leadership belongs to the county administrative board...You have to negotiate and be convincing that your idea is the right way forward, and if the others think differently, well, then you have to come up with an ad-hoc solution." (Interview 13)

The citation above shows that potential diverging views are expected to be bridged through discussions. That is interesting, at least when one recalls "the crisis management paradox" (Moynihan 2008), which is identified as the tension between the need for many actors and interactions in a crisis and for them to perform rapid and decisive coordination at the same time."

A terrorist attack on rail-bound traffic would cause vast societal consequences and thereby result in national ramifications. Some interviewees stressed that the mere location of the attack, in the center of Stockholm and close to the political power of the country, would trigger an enormous security apparatus, and information and coordination activities would take place, as one interviewee expressed, "from all over." No single government agency or jurisdiction has the required resources and expertise for coordinated crisis management; thus, once again, interactions over organizational boundaries are needed. MSB is frequently referred to in the interviews due to its mandate to "support the coordination of measures taken 
by local, regional, and national authorities during a crisis or disaster" (Government Bill 2007/98:92). Interviewees expressed expectations of MSB playing a role in allocating additional resources, activating the Swedish National Air Medivac if necessary, and requesting international support as well as playing a role in information sharing. However, the exact meaning of common formulations such as support to coordination and enabling coordination comes across as unclear to some respondents. Thus, a common contradiction arises. On one hand, it seems to be a fundamental assumption that inter-organizational collaboration and horizontal cooperation are desirable in such situations because expertise and resources from many actors are necessary. On the other hand, concepts associated with a hierarchical steering model, such as control, command, and decisive actions, were frequently mentioned as useful during a complex large-scale crisis with rapid developments.

\section{Ideas, Resources and Interactions in Inter- organizational Collaboration}

In this article, the concept of inter-organizational collaboration has been understood as referring to how organizations need knowledge and resources from other organization and therefore need to interact effectively in crisis management networks in order to achieve a common goal. In our endeavor to gain an understanding of the interplay between resources and structures and ideas about how to use them, it was suggested that we benefit from turning to the involved actors themselves. Hence, drawing attention to what both crisismanagement actors and rail-bound traffic actors regard as opportunities for and challenges to collaborative actions, we can better capture and understand interorganizational collaboration in the context of terroristinduced crises targeting rail-bound traffic.

In terms of opportunities, the respondents in this material have discussed how the idea of interorganizational collaboration has earned increased support over the years. The "Samö 2007 exercise" was mentioned as a point of reference for progress. Since then, the actual hazard, in this case terrorism, has drawn more attention, and through that process, the need for collaborative action has emerged. Workshops related to terrorism prevention and various knowledge-sharing activities are seen as steps toward filling the knowledge gap that has resulted from Sweden's limited experience of dealing with actual mass-casualty attacks. Moreover, different players also report that closer inter-agency relations in some cases have resulted in successful collaborations. Most notable among these was the "Programme for Cooperation - Stockholm Region."
In terms of challenges; the ideas, resources, and collaborative networks encompass many twists and turns. We should note that today's complex crises, including terrorism, are assumed to require collaborative efforts. However, at the same time, it appears that the trend towards more horizontal, collaborative networks also give rise to new challenges. Replacing the often contrasted system, that is a more hierarchical response system, with a collaborative network system, is by no means an automatic solution to the demanding organizational challenges associated with complicated crises. Hence, this concluding discussion will address three challenging points; (i) actors appear to work in subnetworks, (ii)a perceived difficulty of concretizing inter-organizational collaboration and (iii) network concepts contribute to our understanding of obstacles to inter-organizational collaboration, however, it contributes with less regarding promising practices

The first point relates to how actors appear to work in subnetworks, or alternatively expressed, in "silos." The Swedish response system builds on the idea of collaborative actions in which many actors' combined resources and knowledge are a precondition for successful crisis management. However, a picture has been revealed in which many actors tend to continue working primarily in already-known constellations. The different subnetworks can be described as having their own frames and behaviors. For example, one can discern major differences between how a subnetwork of first responders operate compared to a network of transportation actors; and in the context of terrorism, intelligence actors emerge as an additional, very central subnetwork. Hence, even though the Swedish response systems is talked about as a major network spanning different sectors and levels, different subnetworks are easily identified. An interesting finding is therefore that the respondents appear to relate to and interpret this reality very differently. According to many respondents, working in silos is perceived as the biggest obstacle to effective inter-organizational collaboration. They underline how networks are working side-by-side, but do not necessarily interact with each other on a deeper level. Interestingly, not all respondents regard the feature of working in silos as a challenge or an obstacle to inter-organizational collaboration. Instead, they argue that one must acknowledge that, to some extent, the many assumed actors in a response are very different, with different functions and different mandates, and it is not time-efficient for all actors to interact during a response. However, this does not mean that increased cross-sectoral preparedness is not desirable. One can conclude that there appears to be many interpretations of the idea of collaborative crisis-management networks. This indicates that today we have a situation 
in which many actors hold very different understandings of what knowledge, resources and interactions are needed in order to enhance preparedness and the capacity to respond to terrorism targeting rail-bound traffic.

A second point relates to a perceived difficulty of concretizing inter-organizational collaboration among actors. The respondents have revealed a frustration with the difficulty of translating the concept of interorganizational coordination into practice during an extraordinary event. How should all actors, interests, perceptions, and goals be organized in practice? Interorganizational collaboration has been put to the test in connection with major preplanned events and sudden crises, but never in an extraordinary terrorism context. The findings in the material underline the difficulties of this particular extraordinary event. The following concerns have been raised: initial sense-making is seen as problematic, and an insufficient mental preparedness for the complexity of a terrorist attack can hinder a rapid sense-making process and rapid decision-making. Confusion remains over procedures to secure incident sites before entering them. Coordination of several incident sites is another challenge, and there are uncertainties about different limiting factors for capacity in terms of resources. It is important to remember that anticipated difficulties must be dealt with under severe time pressure with many players involved. It is therefore noteworthy that no clear mechanisms for resolving potential conflicts seem to exist. What happens if the many actors disagree or take different directions concerning, for example, progress reports, information provided to the public, and decisions on what to do next? Once again, there is a resounding support for collaborative actions in principle, but as these problems illustrate, there is a delicate challenge to turn the idea of inter-organizational collaboration into prompt, effective action in times of an extraordinary crisis.

Theoretically, and third,results point to the inherent complexity of inter-organizational collaboration by networking. The interplay between ideas, resources and their flows within and between inter-organizational networks seems to preclude any unified, systemic understanding. Whereas network concepts contribute to our understanding of inter-organizational collaboration by sharpening our analysis of potential obstacles, it contributes with less regarding promising practices.

To conclude, two main obstacles to interorganizational coordination seem to exist: despite promising practices, extensive work is still carried out in different subnetworks, and players experience difficulties in translating inter-organizational coordination into practical means. A paradox arises: if work continues to be performed in isolated silos, the ability to concretize truly inter-organizational collaboration will be hindered.

\section{References}

22 July Commission in Norway NOU 2012:14, Rapport fra 22. Julikommisjonen, Office of the Prime Minister, Oslo.

ASTOC - Association of Swedish Train Operating Companies, Medlemmar. Avialabe from: http://www.tagoperatorerna.se/medlemmar_3. (Accessed 2015-10-20).

A. Boin, and P. Hart, Organizing for Effective Emergency Management: Lessons from Research, Australian Journal of Public Administration. 69(4) (2010) 357-371.

A. Boin, and F.Bynander, Explaining success and failure in crisis coordination, GeografiskaAnnaeler: Series A, Physical Geography, 97(1) (2014) 123-135.

M. Brans, Challenges to the Practice and Theory of Public Administration in Europe,Journal of Theoretical Politics. 9 (3) (1997) 389-415.

J. Coleman,Foundations of social theory. (Harvard University Press, Cambridge, 1990).

L. Comfort, A. Boin, and C. Demchak, C. (eds.) Designing resilience -preparing for extreme events. (Pittsburg: University of Pittsburg Press, 2010)

L. Comfort, Crisis Management in Hindsight: Cognition, Communication, Coordination, and Control,Public Administration Review. 67 (1) (2007) 189-197.

S. Curnin, C. Owen, D. Paton, C. Trist and D. Parsons, Role Clarity, Swift Trust and Multi-Agency Coordination, Journal of Contingencies and Crisis Management, 23(1) (2015) 29-35.

E. Danielsson, R. Johansson and L Kvarnlöf, Samverkan under räddningsinsatser - En slutrapport från ett forskningsprojekt, RCR Working Paper Series, Mid Sweden University, 2013.

T. Drabek, Community Processes: Coordination in Handbook of Disaster Research(Springer: New York), pp 217-233.

R. Dynes and E. Quarantelli. Organizational Communications and Decision Making in Crisis, The Ohio State Department of Sociology, Disaster Research Center, 1977.

R. Dynes, Organized Behavior in Disaster (Lexington: Lexington Books, 1970).

J. Edelenbos and E-H Klijn, Trust in Complex DecisionMaking Networks: A Theoretical and Empirical Exploration, Administration and Society. 39 (1) (2007) 25 50.

D. Hansén, Crisis and Perspectives on Policy ChangeSwedish Counter-terrorism Policymaking. Dissertation. Swedish National Defence College, 2010.

https://www.msb.se/Upload/Utbildning_och_ovning/Ovning/ Utv\%C3\%A4rdering_Uppf\%C3\%B6ljning/Utvardering/S am\%C3\%B6\%202007.pdf (Accessed: 2010-10-01).

B. Jenkins, Protecting Public Surface Transportation against Terrorism and Serious Crime: An Executive Overview. Report FHWA/CA/OR-2001-29. San Jose: the Mineta Transportation Institute, 2010.

B. Jenkins, Thetransportation threat to surface transportation the challenges of securing public places inThe McGrawHill Homeland Security Handbook: strategic guidance for a coordinated approach to effective security and 
emergency management(McGraw Hill, New York), pp 2131.

N. Kapucu, Collaborative Emergency Management: Better Community Organizing, Better Public Preparedness and Response, Disasters. 32(2) (2008) 239-62.

N. Kapucu, Interagency Communication Networks During Emergencies: Boundary Spanners in Multiagency Coordination, The American Review of Public Administration. 36 (2) (2006) 207-225.

N. Kapucu, Network Governance in Response to Acts of Terrorism: Comparative Analyses (New York: Routledge).

D, Mileti, Disasters by Design: a Reassessment of Natural Hazards in the United States (Washington DC: Joseph Henry Press, 1999).

Ministry of Justice, Regeringskansliets krishantering, Available from:

http://www.regeringen.se/regeringens-

politik/krisberedskap/regeringskansliets-krishantering/ (Accessed: 2014-12-10).

D. Moynihan, Combining Structural Forms in the Search for Policy Tools: Incident Command Systems in U.S. Crisis Management, Governance. 21(2) (2008) 205-229.

D. Moynihan, The Network Governance of Crisis Response: Case Studies of Incident Command Systems, Journal of Public Administration Research and Theory. 19(1) (2009) 895-915.

MSB /Krisberedskapsmyndigheten, Utvärdering and samverkansövning 2007, Available from:

National Board of Health and Welfare, Socialstyrelsens föreskrifter och allmänna råd om katastrofmedicinsk beredskapAvailable from: http://www.socialstyrelsen.se/publikationer2013/2013-546 (Accessed: 2014-04-20).

G. Peters and J. Pierre, Governance without Government? Rethinking Public Administration, The Journal of Public Administration Research and Theory. 8(2) (1998) 223-243.
E. Klijn and J. Koppenjan, Public Management and Policy Networks: Foundations of a network approach to governance, Public Management: An International Journal of Research and Theory, 2(2) (2000) 135-158.

Krisinformation.se Krishanteringens grunder, Available from:http://www.krisinformation.se/web/Pages/Page 1260.aspx (Accessed 2014-03-23).

S.Lennqvist, Education and training in disaster medicine,Scandinavian Journal of Surgery. 94(4) (2005) 300-310.

B. Levitt and J. March, Organizational Learning, Annual Review of Sociology. 14(1) (1988) 319-338.

Program för Samverkan Stockholms Regionen. http://www.pfssr.se/ (Accessed2014-04-23)

H. Qian, C. Knox and N. Kapucu, What Have We Learned since September 11, 2001? A Network Study of the Boston Marathon Bombings Response, Public Administration Review. 74(6) (2014) 698-712.

R.Rhodes, The New Governance: Governing without Government, Political Studies. 44(4) (2006) 652-667.

E. Stern and B. Sundelius, Crisis Management Europe: An Integrated Regional Research and Training Program,International Studies Perspectives, 3(1) (2002) 71-88.

V. Strandberg, Rail Bound Traffic — a Prime Target for ContemporaryTerrorist Attacks?,Journal of Transportation Security. 6 (3) (2013) 271-286.

W. Waugh, Securing Mass Transit: A Challenge for Homeland Security, Review of Policy Research. 21 (3) (2004) 307- 316.

K. Weick, Enacted Sensemaking in Crisis Situations, Journal of Management Studies. 25(4) (1988) 305-317.

M. Wilmelius and J. Engberg, Crisis Management through Network Coordination: Experiences of Swedish Defence Directors, Journal of Contingencies and Crisis Management. 23(3) (2015) 129-137. 